\title{
Effects of Human Insulin Gene Transfection on the Adipogenic Differentiation of Human Umbilical Cord Mesenchymal Stem Cells in Silk Fibroin Scaffolds in Vitro
}

\author{
Cheng Zhang1, Yi Liu1", Jun Tang1, Meisi Xue', Sijia Min² \\ ${ }^{1}$ Center of Burns and Plastic Surgery, Lanzhou General Hospital, Lanzhou, China \\ ${ }^{2}$ Department of Sericultural Science, Zhejiang University, Hangzhou, China \\ Email: zc5976@yahoo.com, liuyi196402@163.com, 76810762@qq.com, 469896868@qq.com, \\ minsj@zju.edu.cn
}

Received 6 May 2015; accepted 26 June 2015; published 29 June 2015

Copyright (C) 2015 by authors and Scientific Research Publishing Inc.

This work is licensed under the Creative Commons Attribution International License (CC BY). http://creativecommons.org/licenses/by/4.0/

(c) (i) Open Access

\section{Abstract}

The resorption of the transplanted fat over time limited the use of autologous fat for the reconstruction of soft tissue defect. Tissue engineering (TE) adipose with silk fibroin scaffold could be a promising substitute for soft tissue filling. In this study, we try to develop a tissue engineering adipose in vitro by seeding silk fibroin scaffold with human umbilical cord mesenchymal stem cells (hUCMSCs) after transfected with recombinant human insulin gene lentivirus. Our aim was to observe the effects of the insulin gene transfection on the adipogenesis of hUCMSCs when cultured with silk fibroin scaffolds. The hUCMSCs infected with recombinant lentiviral pLenti6.3-insulinIRES-EGFP were seeded on silk fibroin scaffolds and cultured in adipogenic differentiation medium for 5 - 7 days. The expression of adipogenic gene PPAR $\gamma$-2 was tested by RT-PCR after 7 days culture of adipogenic induction. The accumulation of cytoplasmic droplets of neutral lipids was assessed by Oil Red 0 staining. The RNA and protein expression of transfected insulin gene in hUCMSCs were detected by QPCR and western blot. The effect of recombinant lentivirus transfection on the growth and proliferation of hUCMSCs was observed by MTT test. We observed that the $2^{-\Delta \Delta C t}$ value of insulin gene expression of hUCMSCs in the transfected group was 300.25 times higher than that in the untransfected group. The western blot showed that a positive band was discerned at the site of a relative molecular mass of $8 \times 10^{3}$ Dalton in transfected group. After adipogenic culture for 7 days, under the fluorescent inverted phase-contrast microscope, after 0il Red 0 staining, a lot of adipocytes appeared in silk fibroin scaffold; round adipose droplets showed intracellularly; the size of the adipocytes was not homogenous, and the density of adipocytes in transfected group was significantly higher than that in untransfected group $(P=0.007, P<0.01)$.

\footnotetext{
${ }^{*}$ Corresponding author.
} 
RT-PCR results showed that the expression of adipogenic gene PPAR $\gamma$-2 in transfected group was much stronger than that in untransfected group. MTT test showed that there was no significant difference in optical density $(A)$ at each time point between transfected group and nontransfected group $(P=0.056, P>0.05)$. And there was also no significant difference in optical density $(A)$ between cell group and cell-scalffold group $(P=0.066, P>0.05)$. We concluded that insulin gene could obviously promote the adipogenic differentiation of hUCMSCs, and a tissue engineering adipose could be constructed by the silk fibroin scaffolds seeded with human insulin gene-modified hUCMSCs effectively in vitro.

\section{Keywords}

Tissue Engineering Adipose, Human Umbilical Cord Mesenchymal Stem Cells, Silk Fibroin, Insulin, Recombinant Lentivirus, Gene Transfection

\section{Introduction}

Soft tissue defect presents an ongoing challenge in plastic and reconstructive surgery after deep burns, trauma or tumor resection. Standard approaches to soft tissue reconstruction include autologous tissue flaps, autologous fat transplantation and alloplastic implants. All these approaches have disadvantages, including donor-site morbidity, implant migration and foreign body reaction. Autologous fat transplantation, with a minimally invasive cannula harvest, has lower donor site morbidity than tissue flaps, but there is an unpredictable degree of resorption of the transplanted fat over time. The limitations of autologous adipose transplantation for soft tissue defect have paved the way for the researchers to view mesenchymal stem cells (MSCs), with their inherent property of selfrenewal and multi-differentiation potential, as an alternate option [1] [2].

A promising solution for these defects is adipose tissue engineering which aims to generate a vascularized adipose tissue with good biocompatibility for the reconstruction of soft tissue in human clinical practice. Tissue engineering depends upon the interaction between cells, scaffolds and biochemical microenvironment to create a biological tissue construct that functionally mimics the tissue of interest. Except the scaffold, the key factors to construct tissue engineering adipose are seed cells and the cytokines which regulate the growth and differentiation of the stem cells. Human umbilical cord mesenchymal stem cells (hUCMSCs), which were recovered postnatally from an umbilical cord, a discarded clinical waste, formed a relatively new seed cell source that had multi differentiation potential and were capable of differentiating, in vitro and in vivo, into adipogenic, chondrogenic, osteogenic as well as neural and cardiomyogenic lineages [3]. It was reported that some factors such as insulin and insulin-like growth factor- 1 could promote the differentiation of the stem cell into adipose [4] [5]. The bind of insulin with the insulin receptor on the surface of the cell could activate the message path of AKT, RAS, $\mathrm{ERK}_{1} / \mathrm{ERK}_{2}$, promote the synthesis and storage of fat and prohibit the lipoclasis and lipo-oxidation [6]. To promote the proliferation and differentiation of the stem cells (hUCMSCs), a plenti expression vector of pLenti6.3insulin-IRES-EGFP was established and was transfected into hUCMSCs in our laboratory; therefore, a foundation for the construction of tissue engineering adipose was settled [7] [8].

A qualified tissue engineered adipose also needs an idealistic scaffold. Silks are naturally occurring polymers that have been used clinically as sutures for centuries. When naturally extruded from insects or worms, silk is composed of a filament core protein, termed fibroin, and a glue-like coating consisting of sericin proteins. In recent years, silk fibroin has been increasingly studied for new biomedical applications due to the ease of availability, the biocompatibility, slow degradability and remarkable mechanical properties of the material [9] [10]. In addition, the ability to control molecular structure and morphology through versatile processability and surface modification options has expanded the utility for this protein in a range of biomaterial and tissue-engineering applications [11].

Three dimensional scaffolds in tissue engineering serve as a platform for complex cell-cell and cell-matrix interactions and mimic the properties of native extracellular matrix [12]. Our team has made porous scaffolds successfully with silk fibroin according the previously reported method [13]. The structure characterization and mechanical property and biocompatibility of the porous scaffold were tested and reported [14]. 
In this study, we evaluate the structural and functional characteristics of a 3D construction of silk fibroin scaffolds seeded with insulin gene-modified human umbilical cord mesenchymal stem cells in vitro, so as to identify the effect of an insulin gene transfection on the activity and proliferation of the hUCMSCs in the tissue engineering adipose.

\section{Material and Method}

\subsection{Materials}

PMD18-T Vector purchased from Takara company (Japan). Lipofectamine 2000, (pLenti6.3-internal ribosome entry site, IRES)—EGFP plasmid, Oliga DNA fragment with insulin gene, pLneti6.3/v5DEST-IRES-EGFP were synthesized in Invitrogen company (UK). Fetal bovine serum was purchased from Lanzhou National Hyclone Bio-Engineering Co. Lanzhou (China). LG-DMEM was a product of Gibco (USA). Polyamine gel, DMSO, trypsin, dexamethasone indomethacin, insulin, 3-isobutyl-1-methylxanthine (IBMX), Red Oil O were all purchased from Sigma Company (St. Louis, MO, USA).

\subsection{The Isolation, Culture and Identification of hUCMSCs}

The use of hUCMSCs was approved by the ethic committee of the Lanzhou General Hospital of Lanzhou Command, China. Three fresh human umbilical cords were obtained from informed consenting parents after delivering a baby in Obstetric and Gynecologic department of Lanzhou General Hospital of Lanzhou Command. The cords were transported to the laboratory at room temperature over short distance. HUMSCs were isolated and cultured and identified according to the methods of Wang and Liu [3] [15]. Briefly, after removal of blood vessels, the mesenchymal tissue was scraped off the Wharton's jelly and centrifuged at $250 \mathrm{~g}$ for $5 \mathrm{~min}$. After centrifugation, the pellets were resuspended in $15 \mathrm{ml}$ of serum-free Dulbecco's modified Eagle's medium containing $0.2 \mathrm{~g} / \mathrm{ml}$ of collagenase and incubated for $16 \mathrm{~h}$ at $37^{\circ} \mathrm{C}$. Next, the cells were washed, resuspended in DMEM containing $2.5 \%$ trypsin, and incubated for $30 \mathrm{~min}$ at $37^{\circ} \mathrm{C}$ with agitation. Finally, cells were washed again, and cultured in DMEM supplemented with $10 \%$ fetal bovine serum and glucose $(4.5 \mathrm{~g} / \mathrm{l})$ in $5 \% \mathrm{CO}_{2}$ in a $37^{\circ} \mathrm{C}$ incubator.

\subsection{The Transfection of Recombinant pLenti6.3/v5DEST-IRES-EGFP with hUCMSCs}

The construction and identification of a pLenti expression vector of pLenti6.3-insulin-IRES-EGFP was carried out according to the method established in our lab [6] [7]. Third passage cells were detached and inoculated into 6-well plate and were divided into 2 groups. Group A was the experimental group with insulin-IRES-EGFP gene transfection; group B was the control group with EGFP gene transfection. Group A and B were added with recombinant pLenti6.3-insulin-IRES-EGFP and pLenti6.3-IRES-EGFP, according to the method established in our lab [8].

\subsubsection{The Determination of the Insulin Gene Expression by QPCR}

The expression of insulin gene and reference gene were detected in the cell sample by QPCR, the Ct value of the insulin target gene and GAPDH reference gene of samples were calculated according to the QPCR reaction curve, a relative quantitation was carried out by means of $\Delta \Delta C t$ method [16]. The reaction setting was carried out in a computer which was connected with the PCR synthesizer, and the result was analyzed by the icycler software and the quantitative values were calculated out. The untransfected cells was taken as control of the target gene.

$\Delta \Delta \mathrm{Ct}=$ (the mean $\mathrm{Ct}$ value of the undeterminated target gene - (the mean $\mathrm{Ct}$ value of the undeterminated reference gene) - (the mean Ct value of the target gene of the control sample - the mean Ct value of the reference gene of the control samples). The expression volume of the gene, $\mathrm{F}=\mathrm{m} 2^{-\Delta \Delta \mathrm{Ct}}$. The primer sequence of the target gene: upstream: 5'-AACACCTGTGCGGCTCTGAC-3', 83bp; Downstream: 5'-TTCCACAATGCCACGCTTCT-3', 279 bp. PCR reaction condition: $95^{\circ} \mathrm{C}, 10 \mathrm{~s}, 60^{\circ} \mathrm{C}, 30 \mathrm{~s}, 70^{\circ} \mathrm{C}, 45 \mathrm{~s}, 30$ cycles.

\subsubsection{Detection of Insulin Protein by Western Blot}

The western blot was carried out in 4 groups; group 1 was the cell supernatant of the untransfected group; group 2 was the cell supernatant of the transfected group; group 3 was the cell lysate of the untransfected group; group 
4 was the cell lysate of the transfected group. The extracellular secretion of the target protein was detected in group 1 and group 2; the intercellular synthesis of target protein was detected in group 3 and group $4.1 \times 10^{5}$ volume of recombinant lentivirus transfected hUCMSCs was collected, the total protein was extracted, the content of the protein was determined by BCA method [17].

\subsection{The Preparation of Silk Fibroin Scaffold for Scanning Electronic Microscope (SEM) Observation}

The silk gland was pulled out with forceps from abdominal side of the 7-day-old fifth instar larvae of B. mori. (provided by Huzhou Academy of Sericulture, China). The middle part of silk glands were taken out and washed twice in ice deionized water, after removal of epthelium, the silk glands were immersed in distilled water to remove most of soluble sericin protein. After that, the residues were collected into a beaker container deionized water and shaken softly for $1 \mathrm{~h}$ at $0^{\circ} \mathrm{C}$. After centrifuged, the aqueous silk fibroin solution (ASF) was obtained, which was used to prepare porous scaffolds. The concentration of ASF was controlled at $2 \mathrm{wt} \%, 4 \mathrm{wt} \%$ and 6 wt $\%$, respectively. The ASF solution with various concentrations was added to 24-well microplates. After placed at room temperature overnight, ASF solution was aggregated and turned into gel. The porous scaffolds were formed by freezing these gels at $-20^{\circ} \mathrm{C}$ for $24 \mathrm{~h}$ followed by lyophilization. Post treatment was performed by soaking porous scaffolds into ethanol for $24 \mathrm{~h}$ followed by air dried. Ethanol treatment was expected to change the mechanical properties of porous scaffolds according the previous study [18]. the silk fibroin scaffold was cut into a size of $1 \mathrm{~cm} \times 1 \mathrm{~cm} \times 0.2 \mathrm{~cm}$ and a size of $0.5 \mathrm{~cm} \times 0.5 \mathrm{~cm} \times 0.2 \mathrm{~cm}$ respectively, and placed into a glass bottle, dipping in LG-DMEM for 24 hours, replenished medium for 3 times. A small piece of silk fibroin was fetched and fixed by glutaraldehyde for SEM observation.

\subsection{Coculture of Insulin Gene-Modified hUCMSCs with Silk Fibroin Scaffold}

A piece of scalfold with the size of $1 \mathrm{~cm} \times 1 \mathrm{~cm} \times 0.2 \mathrm{~cm}$ was put into 12 -well culture plate, $100 \mu$ of suspension of hUCMSCs in the third passage of group A, in a concentration of $3 \times 10^{6} \mathrm{cell} / \mathrm{ml}$, dropped on the scaffold, placed into a $\mathrm{CO}_{2}$ incubator for 3 - 4 hours, later, LG-DMEM medium was added and covered the cell-scaffold complex wholly. It was returned to the incubator. 24 hours later, the medium was replaced by adipogenic inducer, cultured for 5 - 7 days. Red Oil O staining, another piece of complex was fetched and fixed by $4 \%$ glutaraldehyde for 24 hours, and for SEM examination. The hUCMSCs in the third passage of group B was used as control.

\subsection{The Test of Adipogenic Differentiation of the hUCMSCs by RT-PCR}

The expression of PPAR $\gamma$ - 2 of the hUCMSCs was tested by RT-PCR after 7 days culture of adipogenic induction. Total RNA was extracted by Trizol kit. Primer sequence: PPAR $\gamma$-2 (307) bp, upstream: 5'-TTCTCCTATTGACCCAGAAAGC-3', downtream: 5'-CTCCACTTTGATTGCACTTTGG-3'; reference gene: GAPDH (186 bp), upstream 5'-CACCCACTCTCCTCCACCTTTGAC-3', downstream: 5'-TCTCTTCCTCTTGTGCTCTTGC-3'. Reaction system: $10 \times$ PCR buffer II $5 \mu \mathrm{L}, 2 \mathrm{mmol} / \mathrm{l}$ Dntps mixture $5 \mu \mathrm{L}$, downstream primer (20 $\mu \mathrm{mol} / \mathrm{L} 1 \mu \mathrm{L}$ respectively, Taq DNA polymerase $1 \mu \mathrm{L}, 25 \mathrm{mmol} / \mathrm{L}$ MGCl $24 \mu \mathrm{L}$, CDNA template $2 \mu \mathrm{L}$, RNA free water $31 \mu \mathrm{L}$, metered volume to $50 \mu \mathrm{L}$, PCR reaction condition: $94^{\circ} \mathrm{C}, 10 \mathrm{~min}, 94^{\circ} \mathrm{C}$ denaturation $30 \mathrm{~s}$, GAPDH $55^{\circ} \mathrm{C}$, PPAR $\gamma-250^{\circ} \mathrm{C}$ renaturation $30 \mathrm{~s}, 72^{\circ} \mathrm{C}$ elogation $10 \mathrm{~min}$, the amplification production was electrophoresised in agarose at $20 \mathrm{~g} / \mathrm{L}$, observed and photographed under ultraviolet lamp.

\subsection{The Effect of Gene Transfection on the Growth and Proliferation of hUCMSCs by 3-(4,5-Dimethylthiazol-2-yl)-2,5-Diphenyltetrazolium Bromide (MTT)}

A volume of hUCMSCs in the third passage was inoculated into 96-well plate in a density of $1 \times 10^{4} \mathrm{cell} / \mathrm{mL}$, they were divided into transfection group and untransfection group, 6 wells in each group. In transfection group, recombinant pLenti6.3-insulin-IRES-EGFP was added (MOI = 10), according to the method in paragraph 2.4, the same volume of bacteria-free PBS was added to the untransfection group. A volume of cell suspension from 96-well plate was fetched at 1, 2, 3, 4, 5, 6, 7 days and $10 \mu \mathrm{L}$ MTT was added, after incubating for 4 hours in incubator, the supernatant was discarded and $150 \mu \mathrm{L}$ of DMSO was added, mixed for $10 \mathrm{~min}$, absorbance was determined at $490 \mathrm{~nm}$ by ELISA, the cell growth curve was drew. 


\subsection{The Activity Test of hUCMSCs with Gene Transfection on Silk Fibroin 3D Scaffold by MTT Method}

The experiment was divided into cell group and scaffold group. A suspension of hUCMSCs in a concentration of $1 \times 10^{5} \mathrm{cell} / \mathrm{ml}$ from group A in the third passage was prepared, and was dropped into the 96-well plate with a piece of $0.5 \mathrm{~cm} \times 0.5 \mathrm{~cm} \times 0.2 \mathrm{~cm}$ silk fibroin scaffold, this makes the cell scaffold group. Another 12-well plate (without silk scaffold) was seeded with the same volume of cell suspension from group A, this is the cell group. The plate was placed into a $\mathrm{CO}_{2}$ incubator for 4 hours, the cell-scaffold complex was covered by LG-DMEM, they were replaced into the incubator for 5 days, MTT added, the supernatant was discarded after 4 hours in the incubator, the DMSO added, mixed for $10 \mathrm{~min}$, the absorbance of $490 \mathrm{~nm}$ was tested by ELISA.

\section{Statistical Analysis}

The data was expressed as mean $\pm \mathrm{s}$, a statistical soft of SPSS13.0 was used to analyze the data with a Student's $\mathrm{t}$-test. $\mathrm{P}$ value less than 0.05 is deemed that the difference is significant.

\section{Result}

\subsection{SEM Observation of the Silk Fibroin Scaffold before and after Adipogenic Induction}

The silk fibroin scaffold possesses a natural porus 3D spatial structure, the aperture is uniform in the internal scaffold, and interconnected each other, the aperture is $50-60 \mu \mathrm{m}$, the porosity is up to $90 \%$ (Figure 1). After adipogenic induction culture for 2 weeks, the hUCMSCs differentiated into rounded adipocytes and a lot of extracellular matrix secreted.

\subsection{The Transfection of Recombinant pLenti6.3-Insulin-IRES-EGFP with hUCMSCs}

The recombinant lentiviral vector of co-expressing insulin gene and EGFP gene (pLenti6.3-insulin-IRES EGFP) was successfully constructed. Virus was packaged, purified and concentrated successfully. The virus titer was $1.3 \times 10^{8} \mathrm{TU} / \mathrm{mL}$. The best MOI was 10 and the transfection efficiency was up to $90 \%$ in the same time. Realtime PCR results showed that insulin gene expression of transfected group was positive and non-transfected group was minimal; QPCR showed the reference Ct value were $28.98 \pm 0.65$ and $26.81 \pm 0.19$ in untransfected and transfected groups respectively, the difference between the two groups was not significant $(\mathrm{P}>0.05)$; the $\mathrm{Ct}$ value of the target gene in the two groups were $33.75 \pm 0.36$ and $23.35 \pm 0.11$ respectively, the difference was significant between the two groups $(\mathrm{P}<0.05)$. The $2^{-\Delta \Delta C t}$ value in the transfected group was 300.25 times higher than that in the untransfected group. The western bolt showed that a positive band was discerned at the site of relative molecular mass of $8 \times 10^{3}$ Dalton in group 3 and group 4; but none in group 1 and group 2; the positive

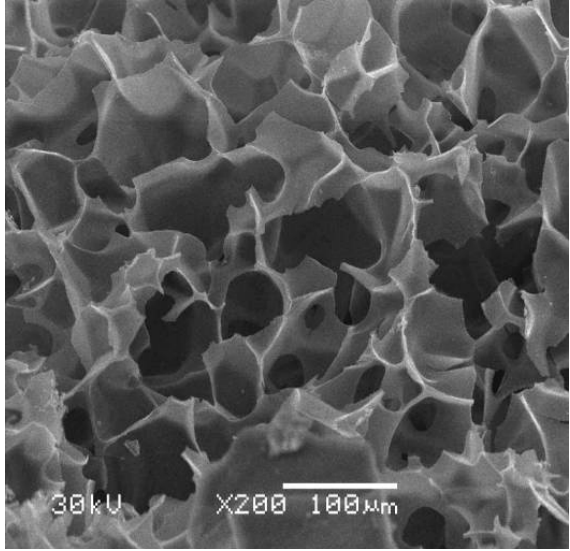

(a)

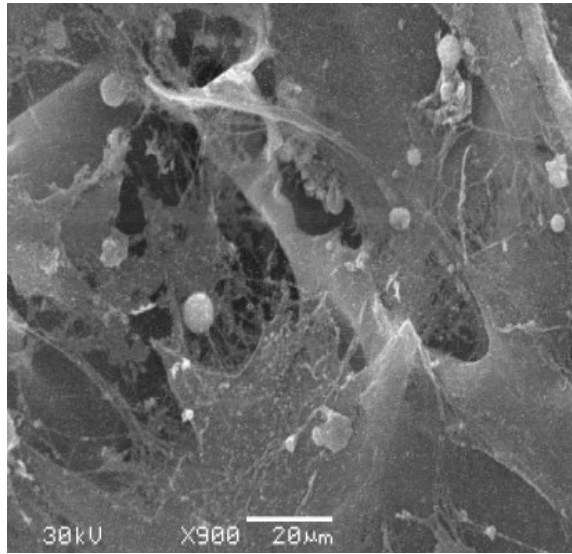

(b)

Figure 1. Silk fibroin scaffold under SEM, before and after coculture with hUCMSCs. (a) Silk fibroin scaffold (SEM, ×200); (b) Cell-scaffold complex, 2 weeks after adipogenic induction (SEM, ×900). 
insulin bands were discerned at the $8 \times 10^{3}$ Dalton in group 2 and group 4, but none in group 1 and group 3 (Figure 2).

The hUCMSCs was transfected in MOI $=10$, observed under inverted phase-contrast microscope, it was found the fluorescent distributed in green hUCMSCs (Figure 3), revealing that the hUCMSCs was transfected with insulin-pLentivirus vector successfully, and the transfection efficacy was (90.18 \pm 1.04$) \%$, and could secret insulin actively.

\subsection{The Result of Coculture of hUCMSCs with Silk Fibroin Scaffold}

The hUCMSCs showed rounded adipogenic cells under SEM, after adipogenic culture in silk fibroin scaffold in insulin-IRES-EGFP gene transfection group (A) and EGFP gene transfection (group B), secreting a lot of extracellular matrix and covering the scaffold material completely (Figure 3) under the fluorescent inverted phasecontrast microscope. After Oil Red O staining, a lot of adipocytes appeared in silk fibroin scaffold, round adipose droplets showed intracellularly, the size of the adipocytes was not homogenous; the density of adipocytes in group A are much more higher than that in group B, be equal to the $(1.6 \pm 0.2)$ times of group B (Figure 4, Figure 5). The difference of the cell density between the two groups was significant $(P=0.007, P<0.01)$.

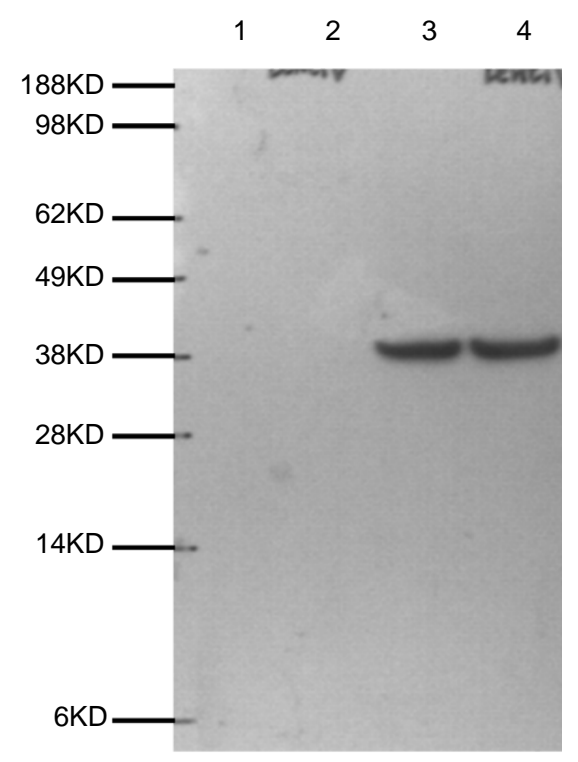

(a)

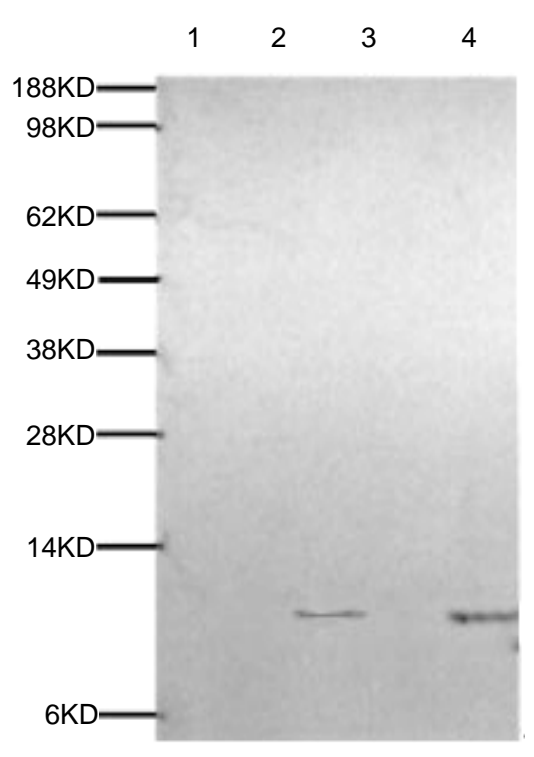

(b)

Figure 2. Western blot results of insulin protein expression in transfected group and nontransfected group. Mr: relative molecular mass. Lane 1: group 1; lane 2: group 2; lane 3 : group 3; lane 4: group 4. (a) GAPDH; (b) Insulin protein.

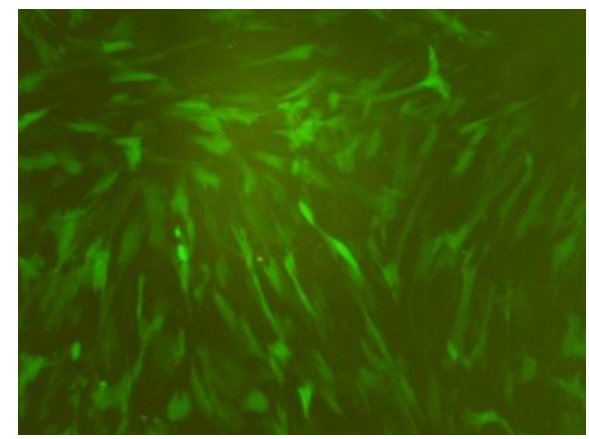

(a)

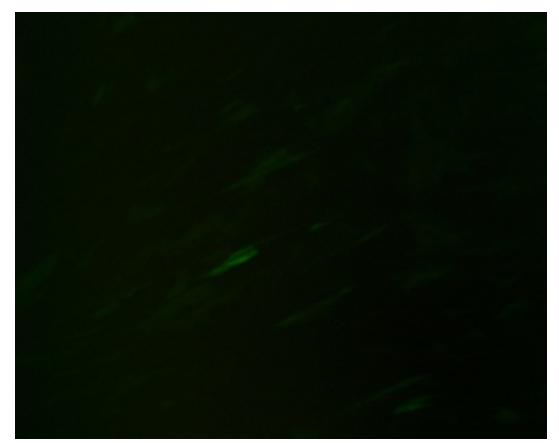

(b)

Figure 3. (a) hUCMSCs being transfected by pLenti6.3-insulin-IRES EGFP at MOI = 10 (fluorescent inverted phase contrast microscopy, $\times 100$ ); (b) Negative control. 


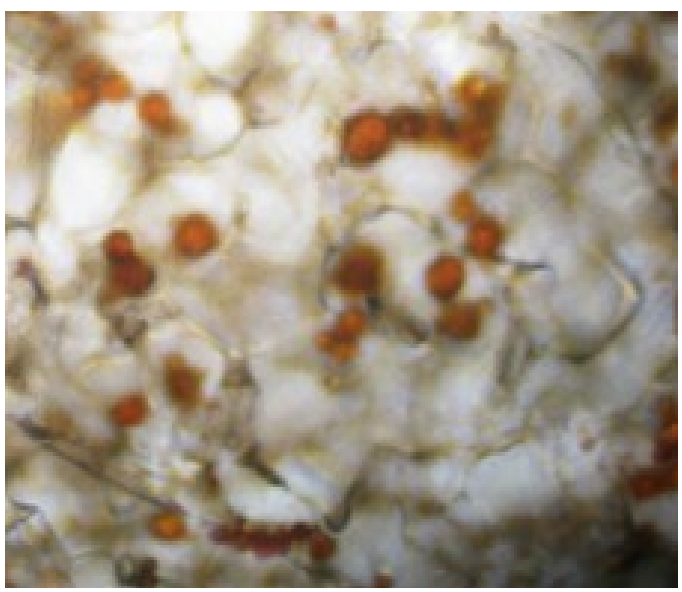

(a)

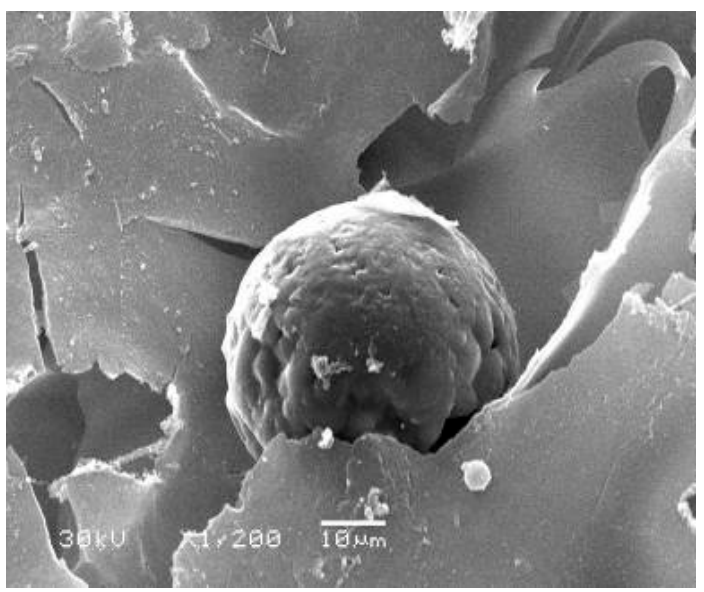

(b)

Figure 4. hUCMSCs transfected by insulin-IRES-EGFP gene seeded in silk fibroin scaffold and adipogenic cultured 7 days in vitro: (a) Oil Red O staining $(\times 100)$; (b) Under scanning electron microscopy $(\times 1200)$.

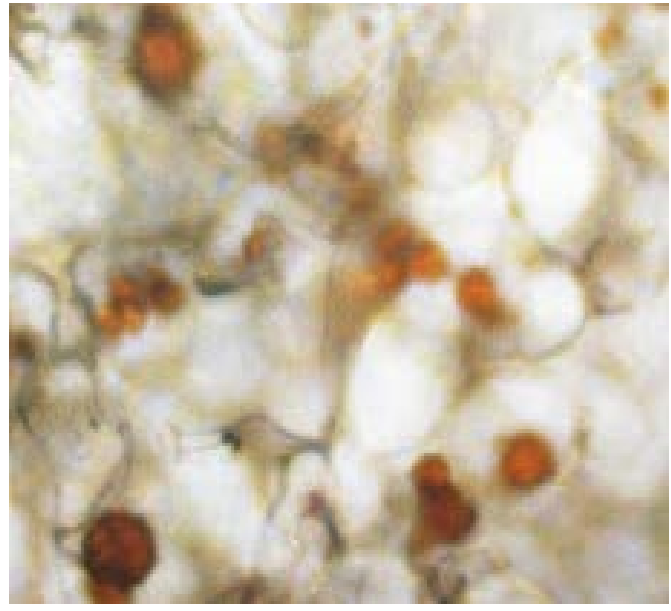

(a)

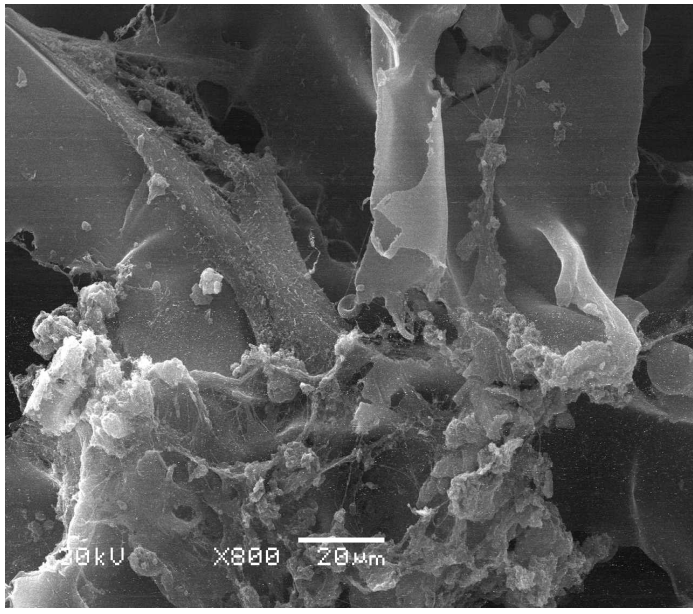

(b)

Figure 5. hUCMSCs transfected by EGFP gene seeded in silk fibroin scaffold and adipogenic cultured 7 days in vitro. (a) Oil Red O stain (×100); (b) Under scanning electron microscopy $(\times 800)$.

Moreover, after the adipogenic induction, hUCMSCs in both group A and B expressed the adipogenic-spesific gene PPAR $\gamma$-2, the expression of PPAR $\gamma-2$ in group A was higher than that in group $\mathrm{B}$ after the semi-quantitative test by RT-PCR. There was no expression of PPAR $\gamma-2$ in uninduced cells. These results demonstrated that hUCMSCs could secret insulin and promote the adipose formation (Figure 6).

\subsection{The Effect of Gene Transfection on the Growth and Proliferation of hUCMSCs}

The MTT results showed that the difference of the absorbance value of hUCMSCs at different time point after the transfection of recombinant pLenti6.3-insulin-IRES-EGFP compared with that in the untransfected group, the difference was not significant $(\mathrm{P}=0.056, \mathrm{P}>0.05)$. This means that the transfection of recombinant lentivirus conferred no significant effectiveness on the growth and proliferation of hUCMSCs (Figure 7).

\subsection{The Activity of hUCMSCs in Silk Fibroin Scaffold after Gene Transfection by MTT Test}

The difference of absorbance in cell group and in cell scaffold group after MTT test was not significant $(\mathrm{P}=$ 0.066, $\mathrm{P}>0.05$ ). The results revealed that the silk fibroin scaffold was not toxic to the growth and proliferation of hUCMSCs after gene transfection (Table 1). 


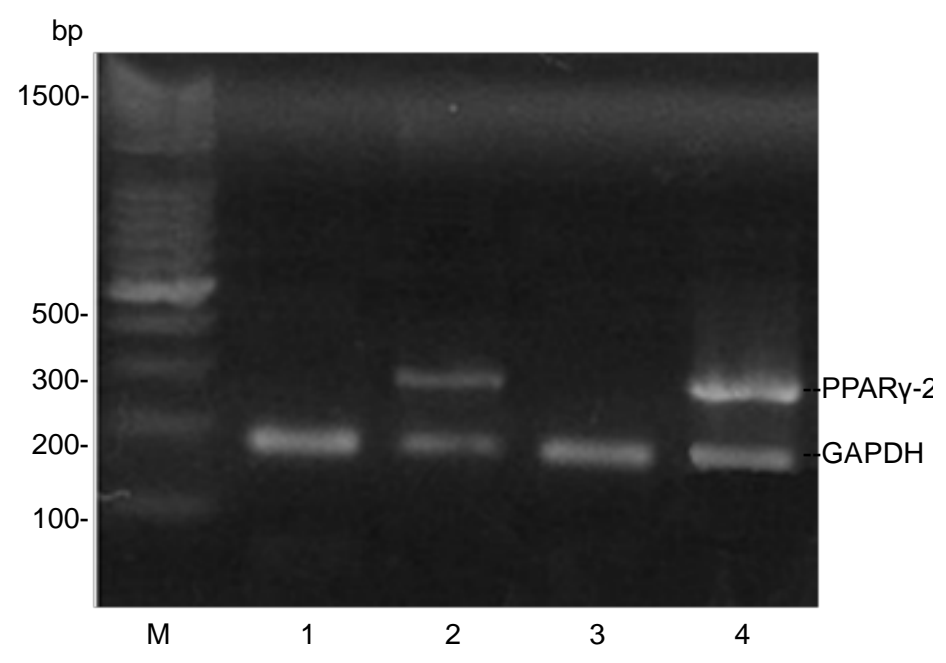

RT-PCR result of adipogenic -specific gene expression of PPAR $\gamma$-2

M: Marker; lane 1: Control group; lane 2: Group B; lane 3: Control group; lane 4: Group A.

Figure 6. RT-PCR result of adipogenic-specific gene expression of PPAR $\gamma$-2.

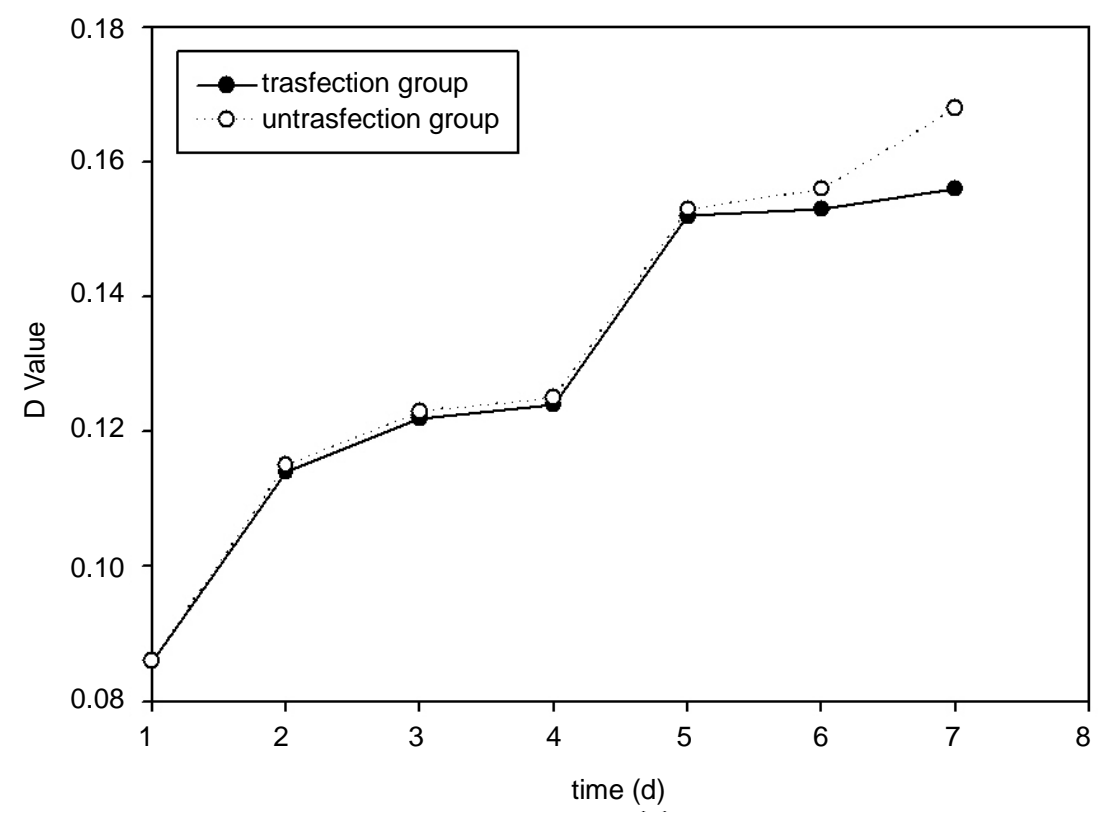

Figure 7. MTT results after hUCMSCs being transfected by insulin-IRES-EGFP gene.

Table 1. Optimal density of hUCMSCs in silk fibroin scaffold in two groups.

\begin{tabular}{cc}
\hline Group & $\overline{\mathrm{X}} \pm \mathrm{S}$ \\
\hline Scaffold group & $1.517 \pm 0.031$ \\
Cell group & $1.715 \pm 0.024^{*}$ \\
\hline
\end{tabular}

*Versus scaffold group, $\mathrm{P}=0.066, \mathrm{P}>0.05$

\section{Discussion}

In this study, the hUCMSCs were chosen as seed cells, because the umbilical cord was an extra-embryonic tissue, possessing a lot of multipotential stem cells which grew fast and was a waste products after fetal disen- 
gagement and easy available. It was reported that adult allo-hUCMSCs just expressed MHC-I, did not express MHCII, therefore, it is promising to be used as allografts to repair tissue defects. More importantly, the proliferation and schizotype of the hUCMSCs permitted the introduction and expression of exogenous gene, so that, it was recommended as a realistic seed cell in adipose tissue engineering [19]-[21].

During the differentiation and proliferation of the seed cells into adipocytes, a special microenvironment and some growth factors are needed to regulate the ability of directed differentiation [22]. Insulin is an important ingredient of the adipogenic induction medium which could regulate the differentiation of the stem cells into the adipocytes. Therefore, in this experiment, it was hypothesis that the transfection of the lentivirus vector with recombinant human insulin into the hUCMSCs could promote the adipogenesis of the hUCMSCs. To decrease the side effects and to realize the location and tracing of the recombinant human insulin gene in vivo, a construction of pLenti6.3-insulin-IRES-EGFP was established [23] [24], this vector could integrate exogenous gene into host chromosomes, a constant expression could be acquired. The transduction efficacy of the target gene increased dramatically, the transfection rate was up to $90 \%$ and was much higher than the transfection rate $(80 \%)$ of the recombinant adennovirus vector to hUCMSCs in our previous work [25]. The results in this study showed that there was no significant difference between the absorbance value of hUCMSCs at different time points in the transfection group and that in the untransfected group $(\mathrm{P}=0.056, \mathrm{P}>0.05)$. The results revealed that the transfection of recombinant lentivirus confer no toxic effectiveness on the growth and proliferation of hUCMSCs (Figure 4, Figure 5). The hUCMSCs could secret insulin actively after transfection of the recombinant human insulin gene, the adipogenic differentiation of the hUCMSCs was promoted (Figure 6). Therefore, we think the low immunogenicity and toxicity of the recombinant lentivirus vector also confer a promising clinical application of the tissue-engineering adipose.

Scaffold is the key factor in the construction of tissue engineering tissues. In this study, we chosed silk fibroin as the scaffold, it possesses a good property of mechanic and biocombatibility, biodegradation, rich source and very cheap. Hofmann's experiment revealed that silk fibroin could not only combine with MSCs in vitro, but also adhere to the preadipocytes and maintain the shape of preadipocytes [26]. On the immunogenicity, Wang [27] reported that during the whole implantation period, all the scaffold showed a good compatibility, the reaction between the animal and the grafts was minimal. Our previous study revealed that an aperture of $50 \mu \mathrm{m}$ of the silk fibroin was of choice in the construction of tissue engineering adipose [28]. Under SEM, the silk fibroin scaffold possesses natural porous 3D spatial structure, the aperture is uniform in the internal scaffold, interconnecting with each other, an aperture of $50-60 \mu \mathrm{m}$, a porosity of $90 \%$, hUCMSCs adhered to the scaffold tightly, grew well, and secreted extracellular matrix. The result of the experiment showed that the scaffold was good for the cell growth. The activity of hUCMSCs in silk fibroin sccaffold after gene transfection by MTT test showed that the difference of the absorbance in cell group and in cell scaffold group, was not significant $(\mathrm{P}=0.066, \mathrm{P}>$ 0.05). These results revealed that the silk fibroin scaffold was not toxic to the growth and proliferation of hUCMSCs after gene transfection.

\section{Conclusion}

In this study, the hUCMSCs were transfected with the recombinant lentiviral vector of co-expressing insulin gene and EGFP gene (pLenti6.3-insulin-IRES EGFP) successfully. The $2^{-\Delta \Delta \mathrm{Ct}}$ value of insulin gene expression of hUCMSCs in the transfected group was 300.25 times higher than that in the untransfected group. After the transfected hUCMSCs seeded in silk fibroin scaffold and adipogenic cocultured for 7 days in vitro, a lot of adipocytes appeared in silk fibroin scaffold; round adipose droplets showed intracellularly; the density of adipocytes in transfected group was significantly higher than that in untransfected group $(\mathrm{P}=0.007, \mathrm{P}<0.01)$. RT-PCR results showed that the expression of adipogenic gene PPAR $\gamma$-2 in transfected group was much stronger than that in untransfected group. We concluded that the transfected insulin gene could obviously promote the adipogenic differentiation of hUCMSCs in a way of autocrine, and a tissue engineering adipose could be constructed by the silk fibroin scaffolds seeded with human insulin gene-modified hUCMSCs effectively in vitro. Therefore, an experimental basis for further construction of tissue engineering adipose in vivo was successfully found.

\section{Funding}

This project is supported by National Natural Science Foundation of China (Grant No. 30872689) and the Key 
Program of Medical Science Research of People's Liberation Army of China during the $12^{\text {th }}$ Five-Year Plan Period (Grant NO. BWS11C061).

\section{References}

[1] Gomillion, C.T. and Burg, K.J.L. (2006) Stem Cells and Adipose Tissue Engineering. Biomaterials, 27, $6052-6063$. http://dx.doi.org/10.1016/j.biomaterials.2006.07.033

[2] Parker, A.M. and Katz, A.J. (2006) Adipose-Derived Stem Cells for the Regeneration of Damaged Tissues. Expert Opinion on Biological Therapy, 6, 567-578. http://dx.doi.org/10.1517/14712598.6.6.567

[3] Wang, H.S., Hung, S.C., Peng, S.T., Huang, C.C., Wei, H.M., Guo, Y.J., et al. (2004) Mesenchymal Stem Cells in the Wharton's Jelly of the Human Umbilical Cord. Stem Cells, 22, 1330-1337. http://dx.doi.org/10.1634/stemcells.2004-0013

[4] Escribano, O., Arribas, M., Valverde, A.M. and Benito, M. (2007) IRS-3 Mediates Insulin-Induced Glucose Uptake in Differentiated IRS-2 Brown Adipocytes. Molecular and Cellular Endocrinology, 268, 1-9. http://dx.doi.org/10.1016/j.mce.2006.12.039

[5] Wang, L. and Detamore, M.S. (2009) Insulin-Like Growth Factor-1 Improves Chondrogenesis of Predifferentiated Human Umbilical Cord Mesenchymal Stromal Cells. Journal of Orthopaedic Research, 27, 1109-1115. http://dx.doi.org/10.1002/jor.20848

[6] Jiang, T., Zhang, D. and Nie, H. (2008) Construction and Expression of the Eukaryotic Expressed Plasmid of MIC3 Gene from Toxoplasma gondii in IBRS-2 Cells. Frontiers of Agriculture in China, 2, 498-501. http://dx.doi.org/10.1007/s11703-008-0075-6

[7] Xue, M.S. and Liu, Y. (2010) Construction of Recombinant Human Insulin Gene Lentiviral Expression Vector and Virus Packaging. Journal of Clinical Rehabilitative Tissue Engineering Research, 14, 6133-6137.

[8] Liu, Y. and Xue, M. (2010) Recombinant Human Insulin Gene Lentivirus Transfecting Human Umbilical Cord Mesenchymal Stem Cells in Vitro. Zhongguo Xiu Fu Chong Jian Wai Ke Za Zhi (Chinese Journal of Reparative and Reconstructive Surgery), 24, 822-827.

[9] Kim, H.J., Kim, H.S., Matsumoto, A., Chin, I.J., Jin, H.J. and Kaplan, D.L. (2005) Processing Windows for Forming Silk Fibroin Biomaterials into a 3D Porous Matrix. Australian Journal of Chemistry, 58, 716-720. http://dx.doi.org/10.1071/CH05170

[10] Horan, R.L., Antle, K., Collette, A.L., Huang, Y.Z., Huang, J., Moreau, J.E., Volloch, V., Kaplan, D.L. and Altman, G.H. (2005) In Vitro Degradation of Silk Fibroin. Biomaterials, 26, 3385-3393. http://dx.doi.org/10.1016/j.biomaterials.2004.09.020

[11] Wang, Y., Kim, H.J., Vunjak-Novakovic, G. and Kaplan, D.L. (2006) Stem Cell-Based Tissue Engineering with Silk Biomaterials. Biomaterials, 27, 6064-6082. http://dx.doi.org/10.1016/j.biomaterials.2006.07.008

[12] Langer, R. and Tirrell, D.A. (2004) Designing Materials for Biology and Medicine. Nature, 428, 487-491. http://dx.doi.org/10.1038/nature02388

[13] Yao, J., Nakazawa, Y. and Asakura, T. (2004) Structures of Bombyx mori and Samia cynthia ricini Silk Fibroins Studied with Solid-State NMR. Biomacromolecules, 5, 680-688. http://dx.doi.org/10.1021/bm034285u

[14] Yang, M.Y., Shuai, Y.J., He, W., Min, S.J. and Zhu, L.J. (2012) Preparation of Porous Scaffolds from Silk Fibroin Extracted from the Silk Gland of Bombyx mori (B. mori). International Journal of Molecular Sciences, 13, 7762-7775. http://dx.doi.org/10.3390/ijms13067762

[15] Liu, Y. and Xiao, H.T. (2010) The Co-Culture of Porus Silk Fibroin Scaffold with hUCMSCs. Chinese Journal of Medical Aesthetics and Cosmetology, 16, 45-48.

[16] Yong, S. and David, J. (2009) Development of a Multiplex qPCR for Detection and Quantitation of Pathogenic Intestinal Spirochaetes in the Faeces of Pigs and Chickens. Veterinary Microbiology, 137, 129-136. http://dx.doi.org/10.1016/j.vetmic.2008.12.020

[17] Le, L.P., Le, H.N., Nelson, A.R., Matthews, D.A., Yamamoto, M. and Curiel, D.T. (2006) Core Labeling of Adenovirus with EGFP. Virology, 351, 291-302. http://dx.doi.org/10.1016/j.virol.2006.03.042

[18] Shao, Z., Young, R.J. and Vollrath, F. (1999) The Effect of Solvents on Spider Silk Studied by Mechanical Testing and Single-Fibre Raman Spectroscopy. International Journal of Biological Macromolecules, 24, 295-300. http://dx.doi.org/10.1016/S0141-8130(98)00093-2

[19] Peng, X., Zhang, X. and Zeng, B. (2008) Locally Administered Lentivirus-Mediated siRNA Inhibits Wear Debris-Induced Inflammation in Murine Air Pouch Model. Biotechnology Letters, 30, 1923-1929. http://dx.doi.org/10.1007/s10529-008-9788-0 
[20] Gordon, D., Glover, C.P., Merrison, A.M., Uney, J.B. and Scolding, N.J. (2008) Enhanced Green Fluorescent Protein-Expressing Human Mesenchymal Stem Cells Retain Neural Marker Expression. Journal of Neuroimmunology, 193, 59-67. http://dx.doi.org/10.1016/j.jneuroim.2007.10.019

[21] Ren, G., Li, T., Lan, J.Q., Wilz, A., Simon, R.P. and Boison, D. (2007) Lentiviral RNA-Induced Downregulation of Adenosine Kinase in Human Mesenchymal Stem Cell Grafts: A Novel Perspective for Seizure Control. Experimental Neurology, 208, 26-37. http://dx.doi.org/10.1016/j.expneurol.2007.07.016

[22] Goomer, R.S., Deftos, L.J., Terkeltaub, R., Maris, T., Lee, M.C., Harwood, F.L., et al. (2001) High-Efficiency Non-Viral Trasfection of Primary Chondrocytes and Perichondrial Cell for ex-Vivo Gene Therapy to Repair Articular Cartilage Defects. Osteoarthritis and Cartilage, 9, 248-256. http://dx.doi.org/10.1053/joca.2000.0382

[23] Blanc, M.R., Anouassi, A., Abed, M.A., Canépa, S., Labas, V. and Bruneau, G. (2009) A New Method to Discriminate Immunogen-Specific Heavy-Chain Homodimer from Heterotetramer Immunoglobulin G Directly in Immunized Dromedary Whole Plasma Proteins: Western Ligand Blotting. Veterinary Immunology and Immunopathology, 127, 340349. http://dx.doi.org/10.1016/j.vetimm.2008.10.334

[24] Chassaigne, H., Trégoat, V., Nørgaard, J.V., Maleki, S.J., van Hengel, A.J. (2009) Resolution and Identification of Major Peanut Allergens Using a Combination of Fluorescence Two-Dimensional Differential Gel Electrophoresis, Western Blotting and Q-TOF Mass Spectrometry. Journal of Proteomics, 72, 511-526. http://dx.doi.org/10.1016/j.jprot.2009.02.002

[25] Li, S.L., Liu, Y. and Hui, L. (2013) Construction of Engineering Adipose-Like Tissue in Vivo Utilizing Insulin Gene-Modified Umbilical Cord Mesechymal Stromal Cells with Silk Fibroin Scaffolds with Silk Fibroin 3D Scaffolds. Journal of Tissue Engineering and Regenerative Medicine, Early View. http://dx.doi.org/10.1002/term.1695

[26] Hofmann, S., Hagenmüller, H., Koch, A.M., Müller, R., Vunjak-Novakovic, G., Kaplan, D.L., et al. (2007) Control of in Vitro Tissue-Engineered Bone-Like Structures Using Human Mesenchymal Stem Cells and Porous Silk Scaffolds. Biomaterials, 28, 1152-1162. http://dx.doi.org/10.1016/j.biomaterials.2006.10.019

[27] Wang, Y., Rudym, D.D., Walsh, A., Abrahamsen, L., Kim, H.J., Kim, H.S., et al. (2008) In Vivo Degradation of Three-Dimensional Silk Fibroin Scaffolds. Biomaterials, 29, 3415-3428. http://dx.doi.org/10.1016/j.biomaterials.2008.05.002

[28] Liu, Y., Xiao, H.T. and Xue, M.S. (2010) The Optimal Aperture Screening: A Suitable Scaffold for the Construction of Tissue Engineered Adipose. Journal of Clinical Rehabilitative Tissue Engineering Research, 14, 1361-1364. (In Chinese) 